Contract No. and Disclaimer:

This manuscript has been authored by Savannah River Nuclear Solutions, LLC under Contract No. DE-AC09-08SR22470 with the U.S. Department of Energy. The United States Government retains and the publisher, by accepting this article for publication, acknowledges that the United States Government retains a non-exclusive, paid-up, irrevocable, worldwide license to publish or reproduce the published form of this work, or allow others to do so, for United States Government purposes. 
Manuscript Number:

Title: Effects of Radiation on Established Forensic Evidence Containment Methods

Article Type: Manuscript

Keywords: Evidence; Containment; Polymer; Forensic; Irradiation

Corresponding Author: Keith L Monson, Ph.D.

Corresponding Author's Institution:

First Author: Caitlin E Ferguson, B.S.

Order of Authors: Caitlin E Ferguson, B.S.;Martine C Duff, Ph.D.;Elliot A Clark, Ph.D.;Glenn K Chapman, A.A.;Jeffrey L Leggitt, M.S.;Keith L Monson, Ph.D.

Abstract: The Federal Bureau of Investigation (FBI) Laboratory is currently exploring needs and protocols for the storage of evidentiary items contaminated with radioactive material. While a large body of knowledge on the behavior of storage polymers in radiation fields exists, this knowledge has not been applied to the field of forensics and maintaining evidentiary integrity. The focus of this research was to evaluate the behavior of several traditional evidentiary containment polymers when exposed to significant alpha, beta, gamma, neutron and mixed radiation sources. Doses were designed to simulate exposures possible during storage of materials. Several products were found to be poorly suited for use in this specific application based on standardized mechanical testing results. Remaining products were determined to warrant further investigation for the storage of radiologicallycontaminated evidence. 


\title{
Effects of Radiation on Established Forensic Evidence Containment Methods
}

\author{
Caitlin E. Ferguson ${ }^{\text {a, Martine C. Duff }}$, Elliot A. Clark ${ }^{\text {a }}$, and Glenn K. Chapman ${ }^{\text {a }}$ \\ ${ }^{a}$ Savannah River National Laboratory \\ Aiken, SC 29808
}

Jeffrey L. Leggitt ${ }^{\mathrm{b}}$ and Keith L. Monson ${ }^{\mathrm{b}}{ }^{*}$,

${ }^{\mathrm{b}}$ Federal Bureau of Investigation, Laboratory Division

Quantico, VA 22135

\begin{abstract}
The Federal Bureau of Investigation (FBI) Laboratory is currently exploring needs and protocols for the storage of evidentiary items contaminated with radioactive material. While a large body of knowledge on the behavior of storage polymers in radiation fields exists, this knowledge has not been applied to the field of forensics and maintaining evidentiary integrity. The focus of this research was to evaluate the behavior of several traditional evidentiary containment polymers when exposed to significant alpha, beta, gamma, neutron and mixed radiation sources. Doses were designed to simulate exposures possible during storage of materials. Several products were found to be poorly suited for use in this specific application based on standardized mechanical testing results. Remaining products were determined to warrant further investigation for the storage of radiologically-contaminated evidence.
\end{abstract}

Key Words: Evidence, Containment, Polymer, Forensic, Irradiation

* Corresponding author, Keith.Monson@ic.fbi.gov, Phone: (703) 632-7847; Fax: (703) 632-7801

Please note that since this is a United States Government work product, therefore there are no copyright restrictions on reproduction, derivative works, distribution, or display of the work (see http://www.usa.gov/copyright.shtml ).

Text to appear in the publication:

This is publication number 10-16 of the Laboratory Division of the Federal Bureau of Investigation. Names of commercial manufacturers are provided for identification only and inclusion does not imply endorsement by the FBI.

This manuscript has been co-authored by Savannah River Nuclear Solutions, LLC under Contract No. DE-AC09$08 S R 2470$ with the U.S. Department of Energy. Specifically, the research was supported by a Work For Others (WFO-A61606709) with the Federal Bureau of Investigation. The United States Government retains and the publisher, by accepting this article for publication, acknowledges that the United States Government retains a nonexclusive, paid-up, irrevocable, worldwide license to publish or reproduce the published form of this work, or allow others to do so, for United States Government purposes. 


\subsection{INTRODUCTION}

\subsection{Background}

Criminal activities involving radioactive materials are a subject of concern internationally. These activities include incidents in which radioactive material is deliberately included and is an important element of the crime as well as incidents in which radioactive material is included unknowingly or without intent to cause harm. Either type of criminal activity may prompt a response by law enforcement authorities. The response is likely to require forensic processing of the radioactive material itself as well as objects that it has contacted. Consequently, the requirements and practices of both forensic sciences and radiological sciences will need to be addressed. Experimental work published by Savannah River National Laboratory (SRNL), the Australian Nuclear Science and Technology Organisation (ANSTO), and the Federal Bureau of Investigation (FBI) have dealt with selected aspects of these requirements and practices [1-3]. The experimental results reported in this paper add to that knowledge base.

For traditional forensics, no aspect is as important to the value of collected evidence as the preservation of its authenticity. In the radiological sciences, the management of contamination and radiation exposure is of the utmost concern. When these two disciplines converge, neglecting the requirements of either specialty may be catastrophic, potentially resulting in irradiation of collectors and handlers, contamination of evidentiary materials and equipment, or the disruption of the chain of custody resulting in admissibility problems as the case reaches the courtroom.

These two scientific fields depend heavily on establishing reliable containment methods and procedures where polymer materials are frequently utilized. It is unknown whether polymer technologies developed for forensic applications, such as tamper proof tapes and evidence bags, can be adapted to address the additional concerns involved when handling radioactive materials. While significant research has been done regarding the structural stability of polymers in radiological environments, investigation must be completed to verify that these items maintain their forensic value under such conditions.

Specific objectives of this investigation were to:

- $\quad$ visually inspect irradiated containment materials to characterize gross physical changes, as these may correlate with, or act as a precursor to, the deterioration of their functionality;

- evaluate samples for irradiation-induced changes in material properties that may compromise their suitability for contaminated evidence containment;

- evaluate containments for changes that may cause complications after evidence storage, including writing obliteration or deterioration; and

- evaluate seals and adjacent areas for radiation effects that may compromise the integrity of the enclosure method.

\subsection{METHODS AND MATERIALS}

\subsection{Test Plan}

A multifaceted approach was taken to characterize the effects of radiation on evidentiary containment materials. Items of interest were exposed to radiation levels representative of levels anticipated if used in storage of contaminated evidence. The various materials were subsequently inspected and tested to determine if these conditions adversely affected the performance of the items. Samples were irradiated by various sources, with each sample receiving one of five irradiation treatments. Specifically, alpha $(\alpha)$, beta $(\beta)$, gamma $(\gamma)$, neutron $(\eta)$, and "mixed-source" irradiation treatments were employed. Post-irradiation tests included both microscopic and visual examination and standardized mechanical testing to examine the quantitative and qualitative effects of the radiation treatments. ${ }^{1}$ Seals, welds, seams and base materials of the samples were inspected, as these were determined to be possible points of failure. Materials were also inspected to determine if effects of radiation could mimic signs of evidence tampering.

\footnotetext{
${ }^{1}$ Standardized mechanical testing completed using American Society for the Testing of Materials (ASTM) test methodologies.
} 
Samples were irradiated to simulate prolonged exposure or high dose radiological material containment. Approximate dose levels were determined by referencing similar experiments previously performed at SRNL. ${ }^{2}$ The body of knowledge regarding polymer behavior in radiological conditions was also consulted [4].

A range of post-irradiation tests was used to determine the effects of the irradiation. Samples were examined by gross visual inspection, stereomicroscopy and scanning electron microscopy (SEM). Test samples were compared to control samples to identify changes in appearance or morphology. Samples cut from exposed items were also mechanically-tested according to standardized ASTM requirements to determine radiation-induced changes in strength and ductility.

\subsection{Materials}

Items currently in use in forensic sciences were evaluated in this investigation. These included:

- $\quad$ aLOKSAK® clear plastic bags ${ }^{3}$, with hermetic seals designed to exclude air, dust, and moisture from reaching enclosed evidence (herein referred to as aLOKSAK® clear bag)

- Griffolyn ${ }^{\circledR}$ 55ASFR white scrim bags ${ }^{4}$, with tear resistance, flame retardant and cold resistance properties (herein referred to as Griffolyn® scrim bag)

- Pink SecoVac ${ }^{\mathrm{TM}}-132$ bags $^{5}$, with anti-static properties (herein referred to as PinkPoly bag)

- $\quad$ ZiprWeld $^{\mathrm{TM}}$ evidence tape ${ }^{6}$, with tamper indication technology

- $\quad$ Saf-T-Pak® STP-104 1.25L secondary pressure vessels ${ }^{7}$ (herein referred to as Saf-T-Pak® container)

- $\quad$ Sarstedt $^{\mathrm{TM}}$ screw cap microtubes ${ }^{8}$ (herein referred to as Sarstedt DNA vial)

- Paper case ID tags

In addition, SRNL also tested several materials currently used at their facility for work with radiological materials. These materials include:

- $\quad$ Aluminized Mylar® heat-seal bags

- 8 mil polyvinyl chloride (PVC), used with radiofrequency (RF) welding technology on-site at SRNL to fabricate containment glovebags of many varieties

Compositions of these items are listed in Table 1.

Table 1: Material Make-Up of Items Under Study

\begin{tabular}{|c|c|}
\hline $\begin{array}{l}\text { Common Name of } \\
\text { Sample }\end{array}$ & Material \\
\hline aLOKSAK® clear bag & Polyethylene \\
\hline Aluminized Mylar® & $\begin{array}{l}\text { Bilayer of thin aluminum sheeting and Mylar }{ }^{\circledR} \text {, a biaxially oriented polyethylene } \\
\text { terephthalate film }\end{array}$ \\
\hline Case ID tag & Paper \\
\hline Evidence tape & Polystyrene film, rubber-based adhesive \\
\hline Glovebag PVC & Polyvinyl chloride, with an unspecified fire retardant component \\
\hline Griffolyn® scrim bag & 2 layers low-density polyethylene, polyester cord grid, fire retardant component \\
\hline PinkPoly bag & Low-density polyethylene, anti-static component \\
\hline Saf-T-Pak® container & Polypropylene \\
\hline Sarstedt DNA vial & $\begin{array}{c}\text { Polypropylene with O-ring of ethylene propylene diene terpolymer solvent-resistant } \\
\text { rubber (EPDM) }\end{array}$ \\
\hline
\end{tabular}

${ }^{2}$ Unpublished SRNL Report SRNL-CST-2008-00002, "Effects of Radiation on Latent Print Development," authored by KB

Martin et al. (2008), was used as a model for the design of this experiment.

${ }^{3}$ Product of LOKSAC Inc., Park City, UT.

${ }^{4}$ Product of Reef Industries, Inc., Houston, TX, USA.

${ }^{5}$ Product of Seco Industries, Commerce, CA, USA

${ }^{6}$ Product of Lynn Peavey Company, Lenneca, KS, USA.

${ }^{7}$ Product of Saf-T-Pak Inc., Edmonton, AB, Canada.

${ }^{8}$ Product of SARSTEDT AG and Co, Nümbrecht, Germany. 


\subsubsection{Sample Preparation}

Some samples required preparation previous to exposure, due to size restrictions associated with several of the radioactive sources and the expected needs for accurate identification of points of failure.

Samples of each material listed in Table 1 were sized to fit the various sources; maximum allowable dimensions for each type of irradiation are listed in Table 2. Samples were configured to include as many prospective points of failure (welds, seams, etc.) as possible, as well as to include the base material.

In addition, samples of the aLOKSAK $®$, Griffolyn ${ }^{\circledR}$, and PinkPoly bags were prepared to mimic their configuration when in use. Case ID tags were introduced into each bag, bags were sealed with evidence tape, and case numbers and information were inscribed in Sharpie ${ }^{\circledR}$ waterproof ink ${ }^{9}$ on the exterior of the bag. These preparatory steps are representative of those taken previous to evidentiary submission for storage. These bags were sized as required by the dimensions of the radioactive source. ${ }^{10}$

Additional samples of heat-welded aluminized Mylar® were prepared and added to the test matrix to observe the effects of radiation on heat welds. Comparison was made between these samples and RF welds present on the glovebag PVC samples to assess these enclosure methods.

The number of samples for each treatment was 13 , resulting in 65 total treated samples and 13 controls.

Table 2: Maximum Sample Dimensions

\begin{tabular}{|l|c|}
\hline Source & Maximum Dimension (cm) \\
\hline & 2.54 diameter \\
\hline Alpha & 5.08 diameter \\
\hline Beta & 15.24 diameter $x$ 20.32 height \\
\hline Gamma & 1.27 diameter $\mathrm{x}$ 3.81 height \\
\hline Neutron & unconstrained \\
\hline Mixed-source & \\
\hline
\end{tabular}

\subsection{Radioactive Sources and Irradiation}

Samples of each material were irradiated by five types of radiation sources. No sample received more than one treatment.

\subsubsection{Alpha Source}

Alpha irradiation of sample materials was completed between February and March of 2009. The source material for $\alpha$ irradiation was an aliquot of plutonium $\left({ }^{239} \mathrm{Pu}\right.$ and $\left.{ }^{240} \mathrm{Pu}\right)$ affixed via flame mounting to a stainless steel planchet. This source was prepared at SRNL. The estimated $\alpha$ activity of the source plate was $2.4 \times 10^{5} \mathrm{~Bq}$. To prevent contamination from the $\mathrm{Pu}$ source, which was potentially dispersible, during sample exposure a double layer of thin Mylar® was placed between samples and the aliquot, resulting in source attenuation of

$\sim 20 \%$. This attenuation is factored in to the following radiation dose values. Samples were irradiated in groups of four arranged across the plane of the planchet, with each exposed directly to the attenuated source and a distance of $<0.01 \mathrm{~cm}$. Activity of exposure was measured prior to the first irradiation and was determined to be $1.92 \times 10^{5} \mathrm{~Bq}$. Samples were exposed for 27 to $192 \mathrm{hrs}$. The total $\alpha$-radiation exposure for each sample is listed in Table 3 in MeV of $\alpha$ activity.

\footnotetext{
${ }^{9}$ Product of Newell Rubbermaid, Oakbrook IL, USA

${ }^{10}$ Results stemming from these stored material proxies are indicated by a superscript lowercase a $\left({ }^{\mathrm{a}}\right)$ throughout this report.
} 
Table 3: Alpha Source Exposures

\begin{tabular}{|c|c|c|}
\hline Sample Description & Exposure Time (hrs) & $\begin{array}{c}\text { Energy from } \\
\text { Irradiation }(\mathrm{MeV}) \\
\end{array}$ \\
\hline Case ID tag & 27.2 & $8.48 \mathrm{E}+10$ \\
\hline Griffolyn ${ }^{\circledR}$ scrim bag ${ }^{\mathrm{a}}$ & 27.2 & $8.48 \mathrm{E}+10$ \\
\hline Griffolyn® scrim bag & 27.2 & $8.48 \mathrm{E}+10$ \\
\hline Heat-sealed Mylar® & 27.2 & $8.48 \mathrm{E}+10$ \\
\hline Sarstedt DNA vial & 93.5 & $2.91 \mathrm{E}+11$ \\
\hline aLOKSAK® clear bag & 137.3 & $4.28 \mathrm{E}+11$ \\
\hline PinkPoly bag & 137.3 & $4.28 \mathrm{E}+11$ \\
\hline PinkPoly bag ${ }^{\mathrm{a}}$ & 137.3 & $4.28 \mathrm{E}+11$ \\
\hline Saf-T-Pak® container & 137.3 & $4.28 \mathrm{E}+11$ \\
\hline aLOKSAK@ clear bag $^{\mathrm{a}}$ & 191.6 & $5.97 \mathrm{E}+11$ \\
\hline Aluminized Mylar® & 191.6 & $5.97 \mathrm{E}+11$ \\
\hline Evidence tape & 191.6 & $5.97 \mathrm{E}+11$ \\
\hline Glovebag PVC & 191.6 & $5.98 \mathrm{E}+11$ \\
\hline
\end{tabular}

\subsubsection{Beta Source}

The $\beta$ irradiation of sample materials was completed between October of 2008 and January of 2009. The source material for irradiation was a sealed strontium (Sr)-90/yttrium (Y)-90 $\beta$ source. A contact dose rate was measured prior to the first sample irradiation and was determined to be nominally $7.44 \mathrm{mGy} \mathrm{hr}^{-1}$. Samples were exposed for 24 to 198 hours. The total exposure in $\mathrm{mGy}$ for each sample is listed in Table 4.

Table 4: Beta Source Exposures

\begin{tabular}{|l|c|c|}
\hline Sample Description & Exposure Time (hrs) & Total Exposure (mGy) \\
\hline & & 187 \\
\hline Evidence tape & 24.2 & 189 \\
\hline aLOKSAK® clear bag $^{\text {a }}$ & 24.4 & 209 \\
\hline Aluminized Mylar® & 27.0 & 210 \\
\hline Heat sealed Mylar® & 27.1 & 211 \\
\hline Griffolyn® scrim bag ${ }^{\text {a }}$ & 27.2 & 321 \\
\hline Saf-T-Pak® container & 41.5 & 348 \\
\hline Griffolyn® scrim bag & 45.0 & 512 \\
\hline Sarstedt DNA vial & 66.1 & 517 \\
\hline Glovebag PVC & 66.7 & 551 \\
\hline PinkPoly bag ${ }^{\text {a }}$ & 71.1 & 562 \\
\hline aLOKSAK® clear bag & 72.5 & 1530 \\
\hline PinkPoly bag & 197.8 & \\
\hline
\end{tabular}

\subsubsection{Gamma Source}

Gamma irradiation of sample materials was completed in November 2008. The J.L. Shepherd Model 109 Dry Cobalt-60 Irradiator, housed by the SRNL Gamma Irradiation Facility, was employed for this series of

irradiations. This instrument allowed for simultaneous in situ irradiation of all sample materials without risk of contamination. Dose rate of the irradiation was estimated to be $3.72 \times 10^{3} \mathrm{~Gy} \mathrm{hr}^{-1}$. Samples were exposed for $26.9 \mathrm{hrs}$. Total radiation absorbed dose for the samples was calculated to be $1.0 \times 10^{5} \mathrm{~Gy}$. 


\subsubsection{Neutron Source}

Neutron irradiation of sample materials was completed between January and February 2009 in the SRNL Neutron Activation Analysis (NAA) facility. This facility houses six doubly-encapsulated Californium (Cf)252 pods totaling $20 \mathrm{mg}$ of source material. The pods are submerged at a depth of $4 \mathrm{~m}$ in concentric tanks of deionized and heavy water, which moderates the thermal $\eta$ flux. Samples were encapsulated inside high density polyethylene containers for insertion and retrieval from the source, resulting in some attenuation. This attenuation is factored in to the following radiation dose values. The estimated thermal $\eta$ flux during exposure was $1.41 \times 10^{7} \eta \mathrm{sec}^{-1} \mathrm{~cm}^{-2}$. Samples were exposed for 15 to $113 \mathrm{hrs}$. Total exposure in $\eta \mathrm{cm}^{-2}$ for each sample is listed in Table 5 .

Table 5: Neutron Source Exposures

\begin{tabular}{|c|c|c|}
\hline Sample Description & Exposure Time (hrs) & $\begin{array}{c}\text { Total Exposure } \\
\left(\eta \mathrm{cm}^{-2}\right)\end{array}$ \\
\hline Griffolyn $®$ scrim bag & 15 & $7.61 \mathrm{E}+11$ \\
\hline Evidence tape & 16 & $8.12 \mathrm{E}+11$ \\
\hline Case ID tag & 23 & $1.17 \mathrm{E}+12$ \\
\hline Aluminized Mylar® & 24 & $1.22 \mathrm{E}+12$ \\
\hline PinkPoly bag ${ }^{\mathrm{a}}$ & 25 & $1.27 \mathrm{E}+12$ \\
\hline aLOKSAK® clear bag $^{\mathrm{a}}$ & 26 & $1.32 \mathrm{E}+12$ \\
\hline Griffolyn $®$ scrim bag ${ }^{a}$ & 41 & $2.08 \mathrm{E}+12$ \\
\hline Sarstedt DNA vial & 43 & $2.18 \mathrm{E}+12$ \\
\hline PinkPoly bag & 64 & $3.25 \mathrm{E}+12$ \\
\hline Saf-T-Pak® container & 64 & $3.25 \mathrm{E}+12$ \\
\hline aLOKSAK® clear bag & 69 & $3.50 \mathrm{E}+12$ \\
\hline Glovebag PVC & 113 & $5.73 \mathrm{E}+12$ \\
\hline Heat-sealed Mylar® & 113 & $5.73 \mathrm{E}+12$ \\
\hline
\end{tabular}

\subsubsection{Mixed-Source Irradiation Facility}

Mixed-source irradiation of sample materials was completed between December 2008 and February 2009. The SRNL E-Wing Shielded Cell Operations (SCO) facility, specifically shielded cell \#4, was employed for this series of irradiations. The shielded cell environment contemporaneously exposed samples to high levels of $\beta$ and $\gamma$ irradiation, as well as low levels of $\eta$ flux. To prevent contamination from ambient (including airborne and particulate) radioactive materials present in the cell, samples were triple bagged in plastic bags prior to their introduction. These barrier layers resulted in some attenuation, estimated at much less than 5\%. The estimated dose rate in shielded cell \#4 during exposure was $16 \mathrm{mGy} \mathrm{hr}^{-1}$. Samples were exposed for a total of 70 days; total radiation absorbed dose for the samples was calculated to be $26 \mathrm{~Gy}$.

\subsection{Mechanical Testing}

Samples were submitted to the SRNL Materials Compatibility and Welding Technology group for mechanical testing. It was determined that the ideal test for evaluating irradiated materials was a standard ASTM International tensile test. Tensile testing provides characterization of mechanical properties by measuring yield strength, tensile strength, elongation at yield, and elongation at break. Samples of appropriate length, $10.16 \mathrm{~cm}$ or longer, were tested using this approach. Control samples of similar dimensions were also tested, for comparison purposes.

Samples that are less than $10.16 \mathrm{~cm}$ in length cannot be characterized by standard tensile testing methods. These samples of limited size were tested using a standardized ASTM punch test. Punch testing, while not standardized to thin plastics, provides qualitative data measuring puncture load, deflection, yield point, and strain of materials. Samples of appropriate size, less than $10.16 \mathrm{~cm}$ in length, were tested using this approach. Control samples were also tested in this method, for comparison purposes. 
While samples evaluated by tensile and punch tests result in the derivation of similar types of qualitative data, values determined from tensile tests are not directly comparable to those determined from punch tests [5]. The literature notes an observed linear relationship between data obtained from these two methodologies; however, this relationship is material-specific and information about materials examined herein was not available [6]. Values in this study were based on comparison of experimental data to control samples of materials tested by the same methodology.

Samples of dimensions problematic to these test methods, specifically the Sarstedt DNA vials, were analyzed by an ASTM method called a "crush" test. Crush testing provides data measuring compressive strength of the item; this is a property of the item and not of the material used to fabricate it. Control samples were also tested in this method, for comparison purposes.

\subsubsection{Tensile Testing}

Tensile testing was performed in close accordance with ASTM standards D882-09 and D638-08 [7-8].

ASTM D882-09 is used for samples less than $1.0 \mathrm{~mm}$ in thickness and requires self-aligning grips to elongate samples at a rate of $50.8 \mathrm{~cm} \mathrm{~min}^{-1}$. This specification applied to the majority of samples in this study.

ASTM D638-08 is used for samples greater than $1.0 \mathrm{~mm}$ in thickness and requires self-aligning grips to elongate samples at a rate of $5.08 \mathrm{~cm} \mathrm{~min}^{-1}$. This specification applied to samples derived from the hard plastic Saf-T-Pak® container.

Slight variations from these standardized methodologies were necessary in the testing of the irradiated samples. The sample dimensions specified in ASTM D882-09, described as a thin strip, were determined to be incompatible with the equipment available at SRNL. Dimensions defined by ASTM D638-08, described as a dog-bone shape, were substituted. When required by the sample size, this dog-bone shape was likewise slightly modified, with dimension ratios maintained when possible. Samples were cut into dog-bone shape using a custom die and die cutter, ensuring uniformity between samples and preventing nicks and tears that could confound testing results. The Saf-T-Pak® container, due to its shape, was cut into appropriate conformation for testing using a computer-controlled cutting device. All resultant dog-bones were examined to verify integrity. Due to limited materials, testing was performed in triplicate or as the sample size would allow. Summary tables indicate the number of repetitions performed for each sample.

\subsubsection{Punch Testing}

Punch tests were performed according to ASTM standard F1342-05 [9]. A probe was fabricated to match the specifications of this methodology. Probe velocity was set at $50.8 \mathrm{~cm} \mathrm{~min}^{-1}$, per the ASTM standard.

Slight variation from this standardized methodology was deemed necessary in the testing of the irradiated samples. Due to limited materials, testing was performed in triplicate or as the sample size would allow.

\subsubsection{Crush Testing}

Crush tests were performed according to ASTM standard D695-08 [10]. Specifically, provisions related to the testing of tubing of less than $2.54 \mathrm{~cm}$ diameter were followed. Samples were subjected to $0.51 \mathrm{~cm} \mathrm{~min}^{-1}$ of compression; testing determined yield point and continued until breakage occurred.

Slight variation from this standardized methodology was necessary in the testing of the irradiated samples. The conformation of samples was not consistent with the standard, as they were tapered rather than perfect cylinders. Also, due to limited materials and the destructive nature of this test, analysis was performed only once for each sample.

\subsection{Visual Examination}

\subsubsection{Gross Examination}

Samples were inspected for visible signs of stretching, cracking, pitting, indentation, and color change including fading. These problems were considered potential points of failure or leak paths and were photographed. 


\subsubsection{Microscopic Examination}

Samples were submitted to the SRNL Materials Non-Destructive Examination (NDE) and Consultation group for examination under stereomicroscope and SEM. Samples were inspected via stereomicroscope to identify cracks, pits and indentations that were considered potential points of failure. Samples exhibiting these features were subsequently examined using the SEM to determine if the abnormality would result in failure or potential failure of the form of containment from which the sample was taken. Defects were photographed.

\subsection{RESULTS}

\subsection{Neutron Activation}

Several samples tested in this experiment generated problematic $\eta$ activation products during exposure to irradiation. These problems occurred in samples exposed to neutron activation and mixed-source irradiation.

Two samples, the Griffolyn ${ }^{\circledR}$ scrim bag and the specially-prepared Griffolyn ${ }^{\circledR}$ scrim bag, caused the activation of a substance initially believed to be sodium-24 ( $\mathrm{t}^{1} / 2$ of 6.23 days) during $\eta$ irradiation in the NAA facility. Samples were allowed to decay for a week and recounted. Levels of the activation product were reduced only by insignificant amounts during this time, likely indicating an unidentified product other than ${ }^{24} \mathrm{Na}$. Samples were discarded as a result of this activation and no data regarding the effects on these samples can be reported.

A single sample, the glovebag PVC, caused the activation of zinc-65 ( $t^{1 / 2}$ of 243.5 days) during $\eta$ irradiation in the NAA facility. Due to the half-life of this compound, it was determined that this sample would not decay to safe levels quickly enough for inclusion in this study. This sample was discarded as a result of this activation and no data regarding this sample were reported.

A single sample from the SCO (mixed-source) facility was delayed in clearance through radiological contamination controls due to residual activity believed to result from $\eta$ activation. The glovebag PVC sample taken from the cell was shown to have lingering $\beta$ activity; the sample was allowed to decay for 24 hrs and was subsequently cleared for further testing. Results from this sample are included in the data presented in this report.

No samples from the $\alpha, \beta$, or $\gamma$ irradiation groups were excluded, since no activation products were produced.

\subsection{Mechanical Testing}

Nine control and 21 treated samples were evaluated using the aforementioned ASTM-based tensile, punch and crush tests. Each sample was divided, allowing for up to three replicate tests of each material to be performed. Speciallyprepared bags (see 2.2.1) and the paper case ID tag were precluded from this type of testing.

\subsubsection{Tensile Testing}

Six control and 17 treated samples were evaluated using the tensile test. Treated samples evaluated by this method included:

- Gamma irradiated samples of aluminized Mylar®, heat-sealed Mylar®, glovebag PVC, evidence tape, PinkPoly bags, Griffolyn ${ }^{\circledR}$ scrim bags, and Saf-T-Pak® containers

- Neutron irradiated samples of heat-sealed Mylar® and PinkPoly bags

- Mixed-source irradiated samples of aluminized Mylar®, heat-sealed Mylar®, glovebag PVC, evidence tape, PinkPoly bags, Griffolyn ${ }^{\circledR}$ scrim bags, and Saf-T-Pak® containers

Samples were tested in triplicate whenever possible given the size of the sample, or as noted in Table 6. "Dogbones" of welded materials, including heat-sealed Mylar ${ }^{\circledR}$ and glovebag PVC samples, were cut to include welds.

Measurements of peak load (a measure of strength, S) and elongation at break (a measure of ductility, E) were monitored throughout the testing for each sample. In Table 6, these values are represented as $\mathrm{S}$ and $\mathrm{E}$.

Changes were observed in both strength and elongation of various sample types. Percentages and direction (increase or decrease in value) of changes are listed in Table 6. 


\subsubsection{Punch Testing}

Eight control and 20 treated samples were evaluated using the punch test. Treated samples evaluated by this methodology included:

- Alpha irradiated samples of aluminized Mylar®, heat-sealed Mylar®, glovebag PVC, evidence tape, PinkPoly bags, Griffolyn® scrim bags, and Saf-T-Pak® containers.

- Beta irradiated samples of aluminized Mylar®, heat-sealed mylar, glovebag PVC, evidence tape, aLOKSAK® clear bags, PinkPoly bags, Griffolyn® scrim bags, and Saf-T-Pak® containers.

- Gamma irradiated samples of the aLOKSAK® clear bag

- Neutron irradiated samples of the aLOKSAK® clear bag, aluminized Mylar® and Saf-T-Pak® container

- Mixed-source irradiated samples of the aLOKSAK® clear bag

Samples were tested in triplicate when possible given the size of the sample. Welded materials (heat-sealed Mylar® and glovebag PVC) were punctured through the weld.

Measurements of peak stress and average indentation at peak stress were monitored throughout testing for each sample. Peak stress was considered an equivalent measurement to peak load or strength in tensile testing, allowing comparison between the two methods. Average indentation at peak stress was considered equivalent to the elongation observed in tensile testing. In Table 6 , these values are represented as $\mathrm{S}$ and $\mathrm{E}$, strength and elongation, for comparison to materials tested via tensile methodology.

Changes were observed in both strength and elongation of various sample types. Percentages and direction (increase or decrease in value) of changes are listed in Table 6.

\subsubsection{Crush Testing}

Three control and 5 treated samples of the Sarstedt DNA vial were tested with this methodology. Vial screwcaps were removed for this test. The peak load was monitored throughout testing for each sample and is an indication of strength of the material. It is represented in Table 6 as an "S" value.

Control samples averaged a peak load of $1673.2 \mathrm{~N}$. The $\eta, \alpha, \beta$, and the mixed-source irradiated samples had similar peak load readings of 1676.1, 1682.6, 1616.5, and 1542.2 N (respectively). The $\gamma$ irradiated DNA vial was the only sample to exhibit significant strength changes. This sample withstood a peak load of $1040.8 \mathrm{~N}$, a decrease of $38 \%$. These results are summarized in Table 6. 
Table 6: Mechanical Testing Summary of Strength (S) and Elongation (E) Showing Increase (+), Decrease (-),

\begin{tabular}{|c|c|c|c|c|c|}
\hline \multicolumn{6}{|c|}{ or No Significant Change (Ø) after Irradiation ${ }^{\text {b,c }}$} \\
\hline & Alpha & Beta & Gamma & Mixed-Source & Neutron \\
\hline \multicolumn{6}{|c|}{ Tested by Tensile Method } \\
\hline $\begin{array}{l}\text { Aluminized } \\
\text { mylar }\end{array}$ & & & S-(8), E-(37) & S-(8), E-(34) & \\
\hline $\begin{array}{c}\text { Griffolyn }{ }^{\circledR} \\
\text { white scrim bag }\end{array}$ & & & $S+(4), E-(61)$ & $\mathrm{S}+(12), \mathrm{E}+(29)$ & $\begin{array}{c}\text { No testing due to } \\
\text { activation }\end{array}$ \\
\hline PinkPoly bag & & & S-(11), E- ${ }^{d}$ & $\mathrm{~S}-(25), \mathrm{E}^{\mathrm{d}}$ & S- $(8), E \emptyset^{f}$ \\
\hline Evidence tape & & & $\mathrm{S} \emptyset(0), \mathrm{E}-(21)^{\mathrm{e}}$ & S-(27), E-(49) ${ }^{e}$ & $\begin{array}{c}\text { Sample } \\
\text { torn/cracked }\end{array}$ \\
\hline $\begin{array}{c}\text { Saf-T-Pak® } \\
\text { container }\end{array}$ & & & S-(19), E-(56) & $s \varnothing(0), E \emptyset(0)$ & \\
\hline $\begin{array}{c}\text { Heat-sealed } \\
\text { Mylar@ }{ }^{\circledR}\end{array}$ & & & $S \varnothing(0), E-(14)$ & $S \emptyset(3), E-(20)$ & $\mathrm{S}-(12), \mathrm{E}-(48)^{\mathrm{e}}$ \\
\hline $\begin{array}{l}\text { Glovebag PVC } \\
\text { yellow-yellow }\end{array}$ & & & S-(22), E-(13) ${ }^{\mathrm{f}}$ & S-(30), E- $(22)^{f}$ & $\begin{array}{c}\text { No testing due to } \\
\text { activation }\end{array}$ \\
\hline \multicolumn{6}{|c|}{ Tested by Punch Method } \\
\hline $\begin{array}{c}\text { aLOKSAK® } \\
\text { small clear bag }\end{array}$ & $\begin{array}{l}\text { No testing due to } \\
\text { sample size }\end{array}$ & $\mathrm{S}+(42), \mathrm{E}+(46)$ & $S+(85), E \emptyset(5)$ & $S+(97), \mathrm{E} \emptyset$ & $\mathrm{S}+(11), \mathrm{E}+(15)$ \\
\hline $\begin{array}{c}\text { Aluminized } \\
\text { mylar }\end{array}$ & $\mathrm{S}+(9), \mathrm{E}+(13)$ & $\mathrm{S}+(10), \mathrm{E}+(4)$ & & & $\mathrm{S}+(14), \mathrm{E}+(12)$ \\
\hline $\begin{array}{c}\text { Griffolyn }{ }^{\circledR} \\
\text { white scrim bag }\end{array}$ & $\mathrm{S} \emptyset(0), \mathrm{E} \emptyset(3)$ & $S+(17), E+(26)$ & & & $\begin{array}{c}\text { No testing due to } \\
\text { activation }\end{array}$ \\
\hline PinkPoly bag & $\mathrm{S}+(29), \mathrm{E}+(51)$ & $S+(26), E+(36)$ & & & \\
\hline Evidence tape & $\mathrm{S}+(15), \mathrm{E}+(14)^{\mathrm{e}}$ & $S \emptyset(0), E-(4)^{e}$ & & & $\begin{array}{c}\text { Sample } \\
\text { torn/cracked }\end{array}$ \\
\hline $\begin{array}{l}\text { Saf-T-Pak® } \\
\text { container }\end{array}$ & $\mathrm{S} \varnothing(0), \mathrm{E} \emptyset(0)$ & $S \emptyset(0), E \emptyset(0)$ & & & $S \varnothing(2), E-(6)^{f}$ \\
\hline $\begin{array}{c}\text { Heat-sealed } \\
\text { Mylar® }\end{array}$ & S-(8), E+(40) & $S \emptyset(2), E-(13)$ & & & \\
\hline $\begin{array}{l}\text { Glovebag PVC } \\
\text { yellow-yellow }\end{array}$ & $\mathrm{S}+(43), \mathrm{E}+(32)$ & $\mathrm{S}+(32), \mathrm{E}+(4)$ & & & $\begin{array}{c}\text { No testing due to } \\
\text { activation }\end{array}$ \\
\hline \multicolumn{6}{|c|}{ Tested by Crush } \\
\hline $\begin{array}{l}\text { Sarstedt DNA } \\
\text { vial }\end{array}$ & $\mathrm{S} \varnothing(0)^{\mathrm{e}}$ & $\mathrm{S} \emptyset(3)^{\mathrm{e}}$ & S- $(38)^{\mathrm{e}}$ & $\mathrm{S} \varnothing(7)^{\mathrm{e}}$ & $\mathrm{S} \emptyset(0)^{\mathrm{e}}$ \\
\hline
\end{tabular}

${ }^{\mathrm{b}}$ Percentages of increase or decrease are shown in parentheses. Percentage values are based on comparison to control samples of materials tested by the same methodology. Values for samples tested by different methods are not directly comparable.

${ }^{\mathrm{c}}$ All samples tested in triplicate unless otherwise indicated.

${ }^{\mathrm{d}}$ Percentage values cannot be provided for this test; control samples exceeded the limits of the testing setup without material failure.

${ }^{\mathrm{e}}$ Tested singularly.

${ }^{\mathrm{f}}$ Tested in duplicate.

\subsection{Visual Observations}

Visible indication of irradiation effects was apparent immediately upon receipt of samples. Samples underwent gross visual changes including color change and damage.

\subsubsection{Color Change}

The most marked visual change between irradiated and control samples was color. Several samples that were exposed to irradiation displayed significant discoloration, developing a yellow to yellow-brown hue. This color change was found in samples exposed to gamma and beta radiation. Affected materials included glovebag PVC, Griffolyn ${ }^{\circledR}$ scrim bags, Saf-T-Pak® container fragments, Sarstedt DNA vials and Case ID tags. Each of these materials has a light-colored base material. It is possible that mild discoloration was present in other samples and was indiscernible due to background. 
Waterproof ink labeling on several of the samples also discolored noticeably after treatment. Samples of the PinkPoly bag and aLOKSAK® clear bag prepared with exterior waterproof ink inscription were found to show lightening and yellowing of the text. Both samples had received a treatment of $\eta$ irradiation.

No other color changes were observed in the other samples by visual inspection.

\subsubsection{Damage}

Resultant damage from treatment was easily visible upon inspection. In some samples, the increased fragility of the material was readily apparent. During handing of the products after irradiation, the items easily split apart. This was observed in the $\beta$-irradiated aLOKSAK® clear bag where, when manipulated, the black zippered portion of the sample separated from the clear body material. Evidence tape applied to the mixed-source and $\eta$ treated clear aLOKSAK ${ }^{\circledR}$ bags likewise became more brittle, with both samples showing heavy cracking along bent surfaces. Fine cracks of a similar nature were found along evidence tape on stored material proxy samples exposed to $\gamma$ radiation.

One further indication of damage to the aLOKSAK® clear bag was a slight alteration in texture and finish in samples treated with $\gamma$ and mixed-source radiation treatments. The $\gamma$ irradiation resulted in a tacky quality developing on the interior of the bag; this surface was sticky to the touch. The sample treated in the shielded cell did not exhibit this quality, but instead displayed a slight melting deformity along the interior seam. It is unknown if this defect was present before treatment.

\subsection{Microscopic Observations}

Samples were examined using a stereomicroscope to identify damaged areas of material with potential to become points of failure or leak paths in the product. Treated and control samples of specially-prepared bags, specifically the aLOKSAK®, were examined and compared. Points of particular interest included welds, seams, areas of discoloration and areas of damage, including cracks within the evidence tape and the fragile junction of zipper and base materials in the aLOKSAK®.

Under stereomicroscopic examination, the results were largely consistent with those from gross observation. Fine cracks were seen in the evidence tape along the sealed surface of samples exposed to $\gamma$ and mixed-source irradiation; heavy cracking was seen in the $\eta$-exposed sample. These defects, while dictating possible failure of the evidence tape, may or may not cause failure of the containment itself. The junction of zippered and base clear materials in the aLOKSAK® was examined carefully. The adhesive appeared sound, and no leak paths were observed.

Multiple other samples were screened in a comparable fashion with no damage identified.

\subsection{DISCUSSION}

The results from mechanical testing, visual inspection and microscopic examination must be analyzed together with extraneous factors to determine the overall effects of irradiation on sample materials.

Mechanically tested samples appear to exhibit a phenomenon previously observed in polymers. Effect on polymers is often closely linked to dose absorbed. Small doses of radiation may increase the strength or ductility of samples, followed by a rapid decrease in one or both properties once a material limit is reached.

The aLOKSAK® clear bag increased in strength under the four mechanically-tested treatments and displayed increased elongation in two of the four samples, with the remaining two samples showing no change in elongation. These results seem to indicate that this polymer is not adversely affected by the types and doses of radiation used in this study. Visual inspection, however, indicated surface texture changes, possible deformity, and increased fragility around the zipper. While points of failure were not confirmed by microscopic examination, the use of this type of containment cannot be recommended without further consideration and testing, including possible changes in permeability of the bags. 
The PinkPoly bag samples increased in strength and elongation after $\alpha$ and $\beta$ exposure. Strength and elongation significantly decreased following both $\gamma$ and mixed-source exposures, indicating a sensitivity to $\gamma$ irradiation. The $\eta$ exposed sample of this material showed a slight decrease in strength and no effect on elongation. Based on these results, this material may be a viable option for long term $\alpha$ or $\beta$ containment, although anti-static properties were not assessed.

The aluminized Mylar® samples increased in strength and elongation when exposed to $\alpha, \beta$, and $\eta$ sources. No physical changes were observed during gross visual and microscopic examinations of these samples. Gamma and mixed-source irradiation decreased the values of both strength and elongation. This indicates that $\gamma$ radiation, present in both treatments, is poorly tolerated by this material even at low doses. As a result, aluminized Mylar ${ }^{\circledR}$ bags would not be recommended for use with $\gamma$ emitting materials, but may be a viable option for $\alpha-, \beta$ - or $\eta-$ emitting evidence.

The heat-sealed Mylar® samples had significantly different results as compared to aluminized Mylar® base material. Heat-sealed samples were more frequently adversely affected by treatment than the unaltered material. Results indicate that the application of a heat seal may compromise the resistance of this material to radiation. This may be caused by the miniscule thinning of the material caused by application of the seal. These results suggest that heat-sealing should not be employed for containment of radiologically contaminated evidence.

The activation products created during $\eta$ treatment of the Griffolyn ${ }^{\circledR}$ scrim bag sample are unidentified; while counting technologies indicated the product ${ }^{24} \mathrm{Na}$, the lack of significant activity degradation after a week (greater than $t^{1 / 2}$ for ${ }^{24} \mathrm{Na}$ ) indicates that another activation product was present. This activation product could not be identified and this method of containment is not recommended for use for evidence emitting $\eta$ flux. Mechanical testing showed a slight increase in strength alongside a significant decrease in elongation in the $\gamma$ irradiated sample. Different effects were shown in the relatively low $\gamma$ dose, mixed-source treatment sample, with increases in both strength and elongation. Based on these results, it appears this containment would only be viable for low dose $\gamma$ emitting evidence. Beta treatment increased values for both mechanical qualities and no effect was seen on $\alpha$ treated samples; the Griffolyn ${ }^{\circledR}$ remains a viable option for containment of these types of radiation at the given doses.

The activation product present in the PVC sample, ${ }^{65} \mathrm{Zn}$, is believed to be resultant from $\eta$ interaction with $\mathrm{Zn}$ present in the material as a stabilizer. Zinc- 65 produces $\gamma$ radiation and its presence within the structure of a form of containment would serve to further compound handling issues. Use of this method of containment for samples emitting $\eta$ flux is not recommended. Samples exposed to $\gamma$ and mixed-source treatments suffered significant strength and elongation decreases, indicating sensitivity to $\gamma$ radiation. Alpha and $\beta$ exposure resulted in increases in strength and elongation at the treatment doses; PVC remains a viable option for containment for these treatments.

The evidence tape samples displayed the most substantial visible degradation of any of the materials. Tape samples from several sources showed cracking and fracturing. Mechanical testing results were somewhat inconsistent, with some treatments strengthening and others significantly weakening. However, because the purpose of evidence tape is to indicate evidence tampering by fracturing when inappropriately handled, the visual changes are much more important than the structural ones indicated by mechanical testing. Cracks caused by irradiation could be inappropriately interpreted as indicators of tampering, and for this reason it is not recommended that this material be used on contaminated evidence.

The Saf-T-Pak ${ }^{\circledR}$ container demonstrated significant decreases in strength and elongation only when exposed to high levels of $\gamma$ radiation. No change was observed in $\alpha, \beta$, and mixed-source treatments, and only slight decrease in elongation was indicated in the $\eta$ exposed sample. Thus, the Saf-T-Pak® container could potentially be used to contain evidence emitting any of these radiation types, when held to appropriate doses.

The Sarstedt vial results showed no change observed in $\alpha, \beta$, mixed-source and $\eta$ exposures and significant decrease in strength and elongation resulting from high-dose $\gamma$ treatment. The Sarstedt vial could potentially be used to contain evidence emitting any of these radiation types, when held to appropriate doses.

The paper case ID tag and waterproof ink markings on the exterior of stored material proxies suffered some degradation from exposure. Both labeling methods displayed notable discoloration from high-dose $\gamma$ treatment, 
causing decreased legibility which would be problematic in application. No effects were observed from $\alpha, \beta$, or $\eta$ exposures.

\begin{tabular}{|c|c|c|c|c|}
\hline Material & Alpha & Beta & Gamma & Neutron \\
\hline Approximate Dose & $\sim 10^{11} \mathrm{MeV}$ & $\sim 300 \mathrm{~Gy}$ & up to $10^{5} \mathrm{~Gy}$ & $\sim 10^{12} \eta \mathrm{cm}^{-1}$ \\
\hline aLOKSAK® clear bag & $x$ & $x$ & $\mathbf{x}$ & $x$ \\
\hline PinkPoly bag & $\checkmark$ & $\checkmark$ & $x$ & $\mathbf{x}$ \\
\hline Aluminized Mylar® & $\checkmark$ & $\checkmark$ & $\mathbf{x}$ & $\checkmark$ \\
\hline Griffolyn ${ }^{\circledR}$ scrim bag & $\checkmark$ & $\checkmark$ & Low only ${ }^{\mathrm{g}}$ & $x$ \\
\hline Glovebag PVC & $\checkmark$ & $\checkmark$ & $\mathbf{x}$ & $x$ \\
\hline Evidence tape & $\mathbf{x}$ & $\mathbf{x}$ & $\mathbf{x}$ & $\mathbf{x}$ \\
\hline Saf-T-Pak® container & $\checkmark$ & $\checkmark$ & Low only ${ }^{\mathrm{g}}$ & $\checkmark$ \\
\hline Sarstedt DNA vial & $\checkmark$ & $\checkmark$ & Low only ${ }^{\mathrm{g}}$ & $\checkmark$ \\
\hline Heat-welding of Mylar® & $\mathbf{x}$ & $\mathbf{x}$ & $\mathbf{x}$ & $\bar{x}$ \\
\hline RF welding of PVC & $\checkmark$ & $\checkmark$ & Low only ${ }^{\mathrm{g}}$ & $\checkmark$ \\
\hline
\end{tabular}

${ }^{\mathrm{g}}$ Indicates suitability for $\gamma$ doses up to several Sv.

Table 7: Usage Summary Indicating Promise for Suitability $(\checkmark)$ or Insuitability $(\mathbf{X})$

\begin{tabular}{|c|c|c|c|c|}
\hline Material & Alpha & Beta & Gamma & Neutron \\
\hline Approximate Dose & $\sim 10^{11} \mathrm{MeV}$ & $\sim 300 \mathrm{~Gy}$ & up to $10^{5} \mathrm{~Gy}$ & $\sim 10^{12} \eta \mathrm{cm}^{-1}$ \\
\hline \multicolumn{5}{|l|}{ aLOKSAK® clear bag } \\
\hline PinkPoly bag & $\checkmark$ & $\checkmark$ & & \\
\hline Aluminized Mylar® & $\checkmark$ & $\checkmark$ & & \\
\hline Griffolyn ${ }^{\circledR}$ scrim bag & $\checkmark$ & $\checkmark$ & & \\
\hline \multicolumn{5}{|l|}{ Glovebag PVC } \\
\hline \multicolumn{5}{|l|}{ Evidence tape } \\
\hline HMRU container & $\checkmark$ & $\checkmark$ & Low only ${ }^{g}$ & $\checkmark$ \\
\hline Sarstedt DNA vial & $\checkmark$ & $\checkmark$ & Low only ${ }^{\mathrm{g}}$ & $\checkmark$ \\
\hline \multicolumn{5}{|l|}{ Heat-welding of Mylar® } \\
\hline RF welding of PVC & $\checkmark$ & $\checkmark$ & Low only ${ }^{\mathrm{g}}$ & $\checkmark$ \\
\hline
\end{tabular}

${ }^{\mathrm{g}}$ Indicates suitability for $\gamma$ doses up to several $\mathrm{Sv}$.

\subsection{CONCLUSIONS}

The evidentiary containment items tested within this study, while exposed to different types of ionizing radiation ( $\alpha$, $\beta, \gamma, \eta$, and mixed), each displayed some negative effect from treatment indicating that all items are susceptible to ionizing radiation. Each type of radiation caused different effects on specific items.

Items exhibiting potential applicability as containment for $\alpha$-emitting evidence include the aluminized Mylar® bag, the Griffolyn ${ }^{\circledR}$ bag, the PinkPoly bag, the Saf-T-Pak® container, the Sarstedt DNA vial, and the glovebag PVC.
Comment [KLM1]: Web version

Comment [KLM2]: Print version 
Items exhibiting potential applicability as containment for $\beta$-emitting evidence include the aluminized Mylar ${ }^{\circledR}$ bag, the Griffolyn ${ }^{\circ}$ bag, the PinkPoly bag, the Saf-T-Pak® container the Sarstedt DNA vial and the glovebag PVC. The aLOKSAK® may also be viable, if its integrity can be proven.

Items exhibiting potential applicability as containment for $\eta$-emitting evidence include the aluminized Mylarß bag, the Saf-T-Pak ${ }^{\circledR}$ container, and the Sarstedt DNA vial. The aLOKSAK ${ }^{\circledR}$ may also be viable, if its integrity can be proven.

Results from this investigation indicate that no material tested escapes detrimental effects when exposed to high levels $\left(\sim 10^{5} \mathrm{~Gy}\right)$ of $\gamma$ irradiation. The aLOKSAK® may be viable, if its integrity can be proven. Despite this, several samples display the potential for use with these materials if containment can be replaced before high doses are reached. The Saf-T-Pak $®$ container and Sarstedt vial appear to have a good level of resistance to $\gamma$ irradiation if maintained under their dose threshold. Dose thresholds were not determined by this study.

For greater specificity as to the dose range in which given materials could potentially be functional, further research with a stepwise dosage approach must be completed. This type of in-depth investigation into individual materials would allow for material thresholds to be determined.

Similarly, study and analysis is needed regarding the interaction these containment materials may have with the evidence contained within them. It is known that high $\beta$ radiation levels can cause metallic samples to produce $\gamma$ irradiation; likewise, $\eta$ activation may potentially create $\gamma$ or $\beta$ emitters. This secondary radiation results from the Bremsstrahlung phenomena and occurs when the primary radiation particle ( $\beta$ or $\gamma)$ interacts with dense (high Z) materials. More investigation into how the composition of the contained materials may affect the containment is recommended.

Finally, further research is recommended on the structural integrity of these materials after exposure. While this study demonstrates that materials are affected by exposure and can conclude that weakening and/or strengthening occurs, it can make no determination as to whether or not these observed changes would result in failure of the container when applied as evidentiary containment.

\subsection{ACKNOWLEDGEMENTS}

We thank Myra Pettis and John Gordon for assistance in the preparation of materials for irradiation. We thank David C. Beam, David Diprete, Mira Malek, Carolyn Conley, Myra Pettis, and the technicians of SRNL SCO for their efforts in the irradiation of sample materials and preparation of the Pu and Sr sources. We thank Lin Thacker and Tony Curtis for assistance with stereomicroscope and SEM analyses. We thank Benjamin Garrett and James Blankenship of the FBI Laboratory, as well as anonymous reviewers, for their helpful comments.

\subsection{REFERENCES}

[1] Duff MC, Crump SL, Ray RJ, Cotham WE, Lamont S, Beals D, Mount K, Koons RD, Leggitt J (2008). Solid phase microextraction sampling of high explosive residues in the presence of radionuclides and radionuclide surrogate metals. J. Radioanal. Nucl. Chem., 275(3):579-593.

[2] Colella MC, Parkinson A, Evans T, Lennard C, Roux C (2009). The recovery of latent fingermarks from evidence exposed to ionizing radiation. J. Forensic Sci., 54(3):583-590.

[3] Scientific Working Group on the Forensic Analysis of Chemical, Biological, Radiological, and Nuclear Terrorism, SWGCBRN (2009). Quality Assurance Guidelines for Laboratories Performing Forensic Analysis of Radiological Materials. Manuscript submitted for publication in Forensic Sci. Communic. (copy on file with author).

[4] Nimitz JS, Allred RE, Gordon BW, Nigrey PJ, and McConnell PE (1994). Chemical Compatibility Testing Final Report Including Test Plans and Procedures. Sandia National Laboratories, Albuquerque, NM, 87185. 
[5] Kurtz SM, Jewett CW, Bergström JS, Foulds JR, and Edidin AA (2002). Miniature Specimen Shear Punch Test for UHMWPE used in Total Joint Replacements. Biomaterials, 23(9):1901-1919.

[6] Hankin GL, Toloczko MB, Hamilton ML and Faulkner RG (1998). Validation of the shear punch-tensile correlation technique using irradiated materials. J. Nuc. Materials., 258-263(2):1651-1656.

[7] D882-09, "Standard Test Method for Tensile Properties of Thin Plastic Sheeting." American Society for Testing and Materials. Accessed 1 April 2009.

[8] D638-08 "Standard Test Method for Tensile Properties of Plastics." American Society for Testing and Materials. Accessed 1 April 2009.

[9] F1342-05 "Standard Test Method for Protective Clothing Material Resistance to Puncture." American Society for Testing and Materials. Accessed 1 April 2009.

[10] D695-08 "Standard Test Method for Compressive Properties of Rigid Plastics." American Society for Testing and Materials. Accessed 1 April 2009. 
Please note that since this is a United States Government work product, therefore there are no copyright restrictions on reproduction, derivative works, distribution, or display of the work (see http://www.usa.gov/copyright.shtml ).

\section{Text to appear in the publication:}

This is publication number 10-16 of the Laboratory Division of the Federal Bureau of Investigation. Names of commercial manufacturers are provided for identification only and inclusion does not imply endorsement by the FBI.

This manuscript has been co-authored by Savannah River Nuclear Solutions, LLC under Contract No. DEAC09-08SR22470 with the U.S. Department of Energy. Specifically, the research was supported by a Work For Others (WFO-A61606709) with the Federal Bureau of Investigation. The United States Government retains and the publisher, by accepting this article for publication, acknowledges that the United States Government retains a non-exclusive, paid-up, irrevocable, worldwide license to publish or reproduce the published form of this work, or allow others to do so, for United States Government purposes. 